\title{
The crisis in pediatric cardiac transplantation: How soon is now?
}

\author{
Jonathan M. Chen, MD
}
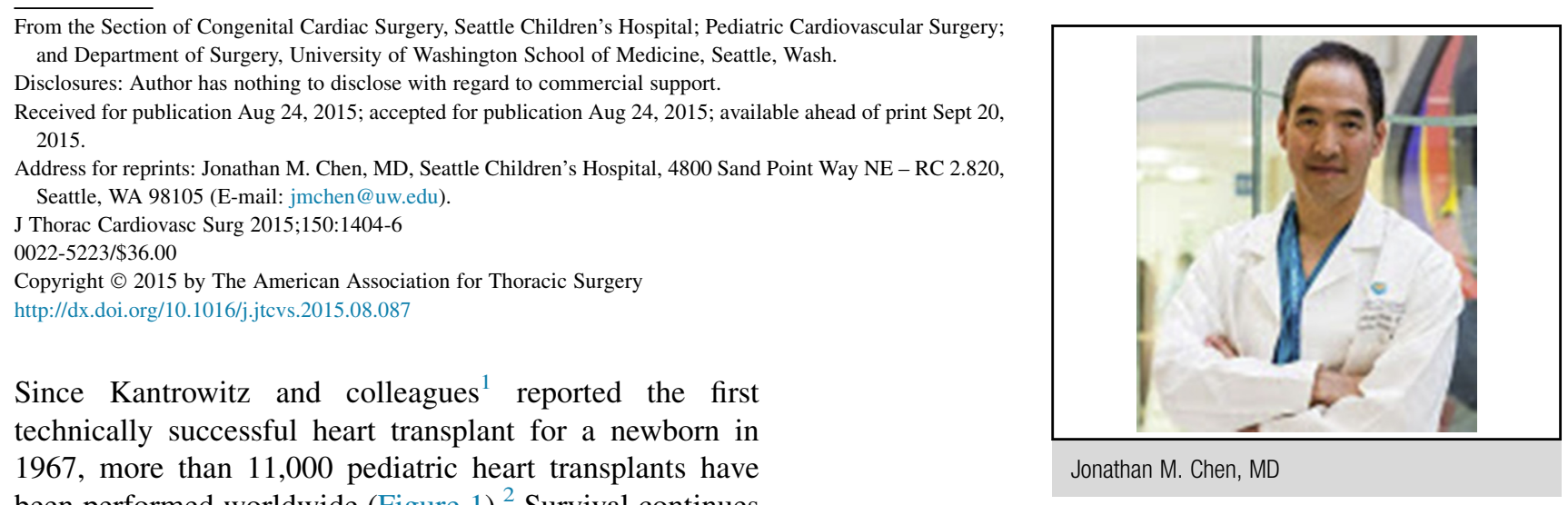

Since Kantrowitz and colleagues ${ }^{1}$ reported the first technically successful heart transplant for a newborn in 1967, more than 11,000 pediatric heart transplants have been performed worldwide (Figure 1 ). ${ }^{2}$ Survival continues to improve, and many pediatric patients previously considered "high risk" because of complex congenital anatomy now represent a sizeable portion of the waiting list at most large centers. Furthermore, improving technology for mechanical ventricular assistance has evolved to support patients who otherwise likely would have died while waiting, so that $25 \%$ of pediatric patients are currently bridged to transplantation with some form of mechanical device. ${ }^{2}$ Despite this, the number of pediatric donors has remained relatively stable over several decades, rendering heart transplantation the best therapy for end-stage heart disease, but benefitting only those fortunate enough to receive this scarce resource.

Evolving in parallel has been improving survival for high-risk newborn and infant operations, most notably for those with complex single ventricle disease. Although remarkable, this success has resulted in many children stalled at the interstage or failing after final palliation for whom total cardiac replacement offers the only true "repair." Paradoxically, this advance has only further accentuated the supply/demand problem of donor availability. Seen in this light, a recurring question emerges: Is pediatric cardiac transplantation truly the answer for heart failure?

Some have described this dilemma as a problem of "inflow and outflow"-namely, that in the absence of a national policy of cadaveric organ conscription (or even presumed consent), only by focusing strategies that improve donor organ yield on the one hand or prevent later graft loss on the other, can we most affect the availability of this therapy and best use donor organs.

For newborns and infants, 2 targeted approaches merit comment. First, although ABO-incompatible heart transplantation has demonstrated itself to have outcomes (with appropriate medical therapy) comparable to ABOcompatible transplants, disappointingly it remains an approach not broadly adopted. ${ }^{3-6}$ Because of the relatively few candidates listed (and even fewer donors available) in the newborn and infant range, many such small-sized organs go unused if allocated solely to blood group-compatible recipients. The impact of a strategy of ABO-incompatible transplantation were it to be obligatory-in particular for those patients in blood group $\mathrm{O}$-would be considerable, and further extending this alternative potentially beyond even those titer and age restrictions previously thought to be prohibitive could allow better use of donor hearts. ${ }^{7}$ Second, our field has been slow to adopt the possibility of donation after cardiac death, despite initial reports of its successful application for newborns in $2008 .^{8}$ Although clearly an ethically sensitive practice, donation after cardiac death may warrant reconsideration in the near future.

For children undergoing heart transplantation, the most dramatic improvements have been in early survival; late results are still burdened by the impact of transplant coronary allograft vasculopathy (CAV) and graft failure. Once diagnosed, generally the only long-term viable alternative is retransplantation, because graft survivalregardless of recipient age-is only $50 \%$ at 5 years after the diagnosis of $\mathrm{CAV}^{9}$ Whether improvements in immunosuppression will affect this disease process remains to be seen, and for children, the ethical considerations of 
multiple retransplantation events over a lifetime are significant.

One of the most disappointing findings in pediatric heart transplantation is the reproducible increase in mortality at 10 to 15 years, when such patients mature through adolescence and early adulthood. This phenomenon is thought largely to be due to medical noncompliance, estimated as high as $10 \%$ in pediatric populations, for whom the risk of mortality is between $25 \%$ and $30 \%$ within 2 years of documented noncompliance. ${ }^{10}$ This preventable late demise accounts for considerable expenditure not only of health care resource for the treatment of rejection but also of the "wasted" organ itself, and is a finding that the transplant community must address to be worthy guardians of the donor organs.

Pediatric patients increasingly are being considered for transplantation after several prior operations in which exposure to blood, homograft tissue, or ventricular assist devices has rendered them immunologically sensitized by the development of circulating antibodies to human leukocyte antigen proteins. With techniques such as exchange transfusion and plasmapheresis garnered from the ABO-incompatible transplant experience, and with directed therapies to mitigate antibody-mediated rejection (and therefore CAV), recent early outcomes for sensitized pediatric heart transplant recipients have been encouraging, but the late consequences of these advanced therapies are not yet known. ${ }^{11,12}$

For those patients who underwent the Fontan and have developed cirrhosis from long-standing passive congestion, and even more commonly for those heart recipients with concomitant renal failure, recent data would suggest that selected patients may have outcomes with multivisceral transplant (eg, heart-kidney, heart-liver) comparable to those receiving heart transplants alone. Such findings have considerable implications for organ allocation algorithms and even greater ethical repercussions with regard to equitability. In both arenas, a complex interchange emerges between our allegiance as surgeons to an individual patient and the overall impact that multivisceral transplantation strategies confer to all potential candidates of either solid organ alone. Indeed, in this light, it becomes increasingly ambiguous how to determine when "enough is enough."

What is clear is that, on the whole, heart transplantation is an incredibly effective treatment for pediatric heart failure. The donor organ shortage manifests impact as longer waiting times, and by extension death, on the waiting list. However, what governs an individual program's decision to accept or reject a given donor offer ultimately is a composite calculation of likely outcome. In the United States, this assessment is further guided by the fact that

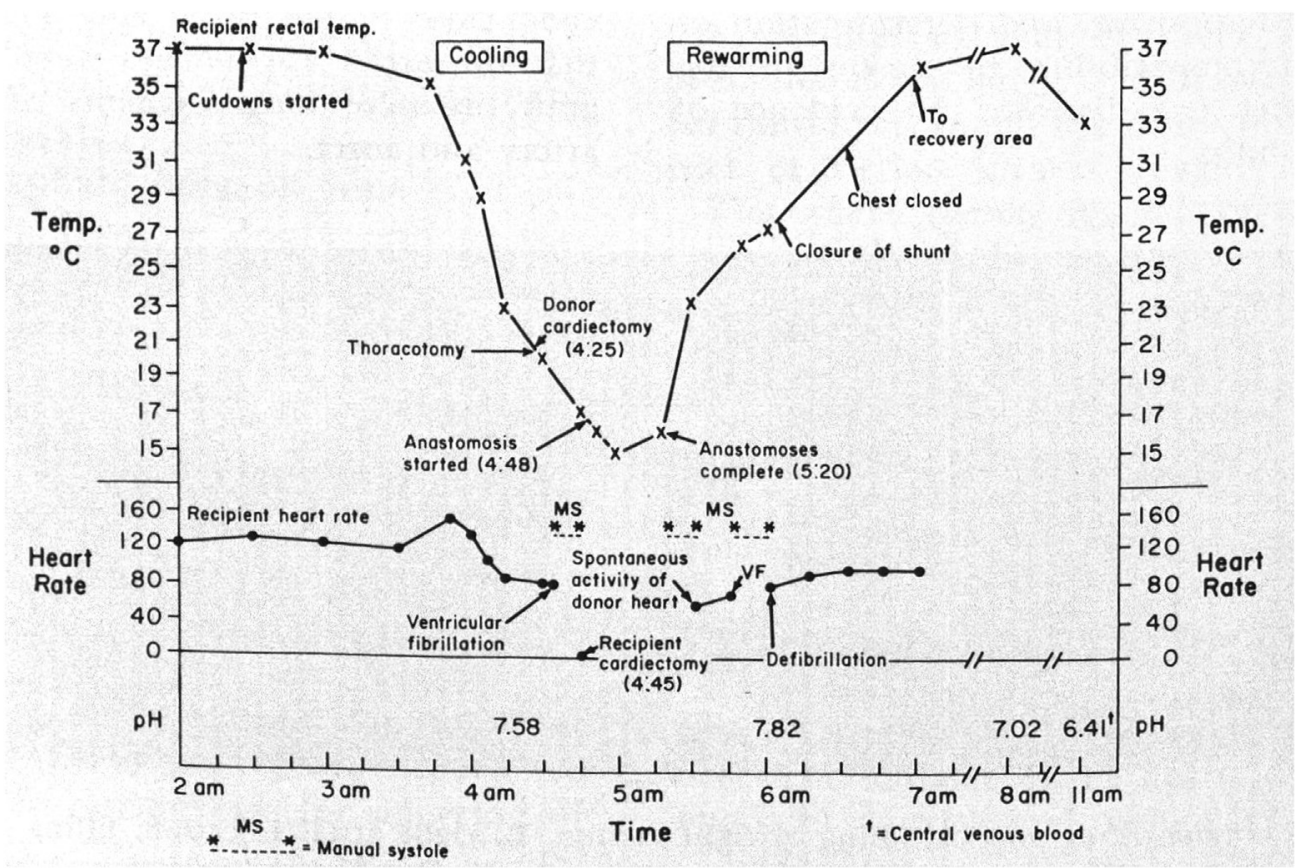

FIGURE 1. Sequence of events during the first successful heart transplant in 1967. ${ }^{1}$ The operation was performed under deep hypothermia with topical cooling in a newborn with tricuspid atresia. The child ultimately died 5 hours after transfer to the recovery room from severe metabolic and respiratory acidosis. Helen Taussig referred to this operation as one that "hurt the medical profession to no end [by] taking unnecessary chances and playing for the gallery" (Kantrowitz A. America's first human transplantation: the concept, the planning, and the furor. ASAIO J. 1988;44:244-52). MS, Manual systole; $V F$, ventricular fibrillation. Reprinted with permission. ${ }^{1}$ 
oversight by the Organ Procurement Transplant Network and United Network for Organ Sharing demands an extremely high rate of early success, lest a program be identified for outcomes below expected values. One could argue that in this sense we are a victim of our own success, and perhaps that these thresholds are too high-wouldn't a given patient rather opt for an $85 \%$ (not $90 \%$ ) rate of immediate success to avoid an increasingly higher rate of dying on the waiting list because of prohibitive wait times? Put another way, what is an "acceptable" waiting list mortality rate?

Unlike in older adults who have comparatively shorter overall life expectancies, the concept of "destination" assist device support is currently beyond the reach of pediatric patients, given their anticipated need for decades of support. However, with further improvements in device durability, novel anticoagulation, and innovative energy sources, one could surely imagine a day in which the best durable implantable device could be as efficacious as today's allograft. In truth, shy of a dystopian Ishiguro future of Hailsham students who are professional donor organ sources (and assuming xenotransplantation remains a therapy forever in the future, to paraphrase Shumway), long-term device support may be our only hope for a meaningful impact on the donor organ shortage. ${ }^{13}$ Nowhere else in the field of medicine (in the developed world) is the availability of an overwhelmingly successful therapy limited solely by resource. Because of this, in the meantime, our push must be toward helping the inflow and limiting the outflow. Public awareness of the necessity of organ donation in concert with the strategies outlined all must be deployed simultaneously if we are to be able to offer pediatric patients their best longterm therapy for heart failure.

\section{References}

1. Kantrowitz A, Haller JD, Joos H, Cerruti MM, Carstensen HE. Transplantation of a heart in an infant and an adult. Am J Cardiol. 1968;22: 782-90.

2. Dipchand AI, Edwards LB, Kucheryavaya AY, Benden C, Dobbels F, Levvey BJ, et al. The registry of the international society for heart and lung transplantation: seventeenth official pediatric heart transplantation report-2014; Focus theme: retransplantation. J Heart Lung Transplant. 2014;33:985-95.

3. West LJ, Karamlou T, Dipchand AI, Pollack-BarZiv SM, Coles JC, McCrindle BW. J Thorac Cardiovasc Surg. 2006;131:455-61.

4. Dipchand AI, Pollack BarZiv SM, Manlhiot C, West LJ, VanderVliet M, McCrindle BW. Equivalent outcomes for pediatric heart transplantation recipients: ABO-blood group incompatible versus ABO-compatible. Am J Transplant. 2010;10:389-97.

5. Henderson HT, Canter CE, Mahle WT, Dipchand AI, LaPorte K, Schechtman $\mathrm{KB}$, et al. ABO-incompatible heart transplantation: analysis of the Pediatric Heart Transplant Study (PHTS) database. J Heart Lung Transplant. 2012;31:173-9.

6. Almond CS, Gauvreau K, Thiagarajan RR, Piercey GE, Blume ED, Smoot LB, et al. Impact of ABO-incompatible listing on wait-list outcomes among infants listed for heart transplantation in the United States: a propensity analysis. Circulation. 2010;121:1926-33.

7. Urschel S, Larsen IM, Kirk R, Flett J, Burch M, Shaw N, et al. ABO-incompatible heart transplantation in early childhood: an international multicenter study of clinical experiences and limits. J Heart Lung Transplant. 2013;32:285-92.

8. Boucek MM, Mashburn C, Dunn SM, Frizell R, Edwards L, Pietra B, et al. Pediatric heart transplantation after declaration of cardiocirculatory death. $N$ Engl J Med. 2008;359:709-14.

9. Kindel SJ, Law YM, Chin C, Burch M, Kirklin JK, Naftel DC, et al. Improved detection of cardiac allograft vasculopathy: a multi-institutional analysis of functional parameters in pediatric heart transplant recipients. J Am Coll Cardiol. 2015;66:547-57.

10. Oliva M, Singh TP, Gauvreau K, VanderPluym CJ, Bastardi HJ, Almond CS. Impact of medical non-adherence on survival after pediatric heart transplantation in the USA. J Heart Lung Transplant. 2013;32:881-8.

11. Castelberry C, Ryan TD, Chin C. Transplantation in the highly sensitized pediatric patient. Circulation. 2014;129:2313-9.

12. Asante-Korang A, Amankwah EK, Lopez-Cepero M, Ringewald J, Carapellucci J, Krasnopero D, et al. Outcomes in highly sensitized pediatric heart transplant patients using current management strategies. J Heart Lung Transplant. 2015;34:175-81.

13. Ishiguro K. Never Let Me Go. New York: Alfred A. Knopf; 2005. 